\title{
A la FMH, la communication est un éventail qui fait bouger les choses
}

Depuis le début du mois d'août, je dirige le département de la communication de la FMH. Après des études de langue et de littérature allemande et française et un détour par l'enseignement, je travaille depuis sept ans dans la communication, dans le domaine de la santé. J'ai acquis mon expérience et mes connaissances entre autres comme journaliste, dans la communication d'entreprise d'une caisse-maladie, comme conseillère en relations publiques pour des hôpitaux et dans l'industrie pharmaceutique et de la technologie médicale.

Forte de plus de 30000 médecins, la FMH est une des plus grandes associations professionnelles de Suisse. On remarque toutefois rapidement que la force due au nombre a aussi son revers, celui de l'hétérogénéité. A la FMH, les médecins proviennent des quatre régions linguistiques, ils se différencient par leurs nombreuses spécialités, et pratiquent comme salariés en milieu hospitalier ou comme indépendants. La pluralité des membres et, partant, de leurs opinions peut souvent paraître pénible et chronophage; simultanément, le corps médical se présente, et la FMH avec lui, comme un large éventail multicolore qui procure de l'air et fait bouger les choses.

La communication de la FMH doit, elle aussi, être remuante et rafraîchissante, à l'intérieur comme à l'extérieur. Pour utiliser cette diversité et ne pas s'y perdre, la FMH et son département de la communication s'emploient à rassembler les nombreuses feuilles multicolores en présence pour en faire un seul éventail, large et solide. Quand elles volètent sans attache, ces feuilles ne produisent rien. Ce n'est qu'après avoir été réunies pour former un éventail qu'elles procurent de l'air et font bouger les choses. De même, il est nécessaire de parler d'une seule voix pour défendre les intérêts de la FMH et soutenir les demandes des médecins envers l'extérieur, par exemple en politique de la santé, face aux médias ou au public. Ce

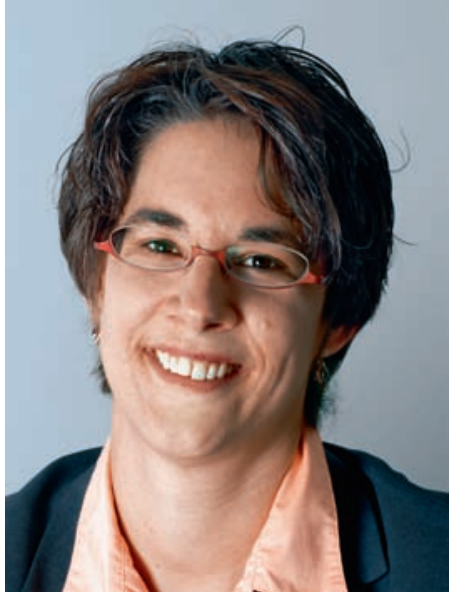

Jacqueline Wettstein

n'est qu'au moment où cette voix sonne avec force qu'elle est prise au sérieux.

En ma qualité de responsable de la communication de la FMH, ma tâche consiste à comprendre les besoins des médecins, à leur procurer l'audience nécessaire au sein du corps médical et à l'extérieur, auprès des organisations de politique de la santé, des médias et du public. Pour y parvenir, il ne s'agit pas de monologuer mais de promouvoir le dialogue. Dans cet esprit, la direction de la FMH et moimême, en ma qualité de responsable de la communication, vous invitons à échanger avec nous. Pour créer un éventail capable de procurer de l'air et du mouvement au sein de notre organisation. Pour parler d'une seule voix afin de nous faire encore mieux entendre à l'extérieur. Je me réjouis d'assumer la tâche qui m'est dévolue et de participer à ces échanges!

Jacqueline Wettstein, responsable de la communication de la FMH 